\title{
Letters to the Editor
}

\section{The Theory of Essence}

To the Editor:

I carefully read Kenneth Arnette's third paper on the theory of essence (Arnette, 1999), in which he referred to some of my comments (Krishnan, 1999) on his second paper (Arnette, 1995). I am afraid that I now cannot help come to the conclusion that there is no entity that answers to his description of the essence.

Before proceeding further, let me point out that, contrary to Arnette's claim (1999, p. 76), I have not said that the essence is material. What I have said, stating reasons, is that all the constituents of the universe are composed of the same order of stuff and therefore, all phenomena should be explicable in terms of interaction of entities belonging to it. It is inconsequential whether we call it matter or something else, because we lay down the criteria for considering what matter is, and there is nothing unalterable about those criteria (Krishnan, 1996). Today I would put the issue in this way: As there is only one order of stuff, we may call it what we like-matter, spirit, God, or something elseprovided we keep in mind that conventional meanings of these labels do not apply. I might add that since I have pointed out that we do not know exactly what matter is (Krishnan, 1999), it should be clear that I could not have said, or meant, that the essence is material.

According to Arnette (1992, pp. 16-17), the essence is the same as what is popularly called the soul or spirit in some cultures. There is no agreement among the believers on questions about its characteristics, origin, and so on; however, they all seem to hold that it is the factor that is ultimately responsible for animating a person and, being the source of life, it is everlasting. I assume that Arnette also accepts this view because he has said that it is the "seat of consciousness" (Arnette, 1992, p. 17) and it is indivisible (Arnette, 1995, p. 95). (Anything indivisible obviously does not break up and perish.)

This traditional view of the essence gives rise to a number of questions. For example, how does the essence come into existence? Arnette did not answer this question, but described only where it comes from, that is, "other universes" (Arnette, 1999, p. 87). But is there 
more than one universe in reality? I raise the question because the word "universe" is usually used in the sense of "all that is." However, if Arnette was employing the word in any special sense, he should reveal that sense and explain the criteria he used for distinguishing one universe from another, as well as how the characteristics or laws of the place of the essence's origin shape its properties.

It is unclear what to make of Arnette's claim (1995, p. 87) that the essence comes to "this universe" to join with a body. Did he mean that the body comes into being before the arrival of the essence, that is, independently of the animating factor? If so, what is the role of the essence in the life of a person?

Equally enigmatic is the suggestion that body-essence interaction is through their respective electric fields (Arnette, 1995). If the body can produce an electric field in order to interact with the essence, does that not mean that it can function without the essence?

Yet another problem is the proposal that the essence is indivisible (Arnette, 1995, p. 95). As pointed out earlier, that suggests that the essence is eternal, unlike any other object known to us. Said another way, essences and the rest of the objects in the universe are composed of two different orders of stuff. But this cannot happen, as there is only one order of stuff. Arnette (1995, p. 96) seemed to agree that the universe is monistic, in the sense I have explained monism, for he wrote that although essence and body are "extremely different," they have something in common. Entities with some common properties cannot be said to belong to different orders of reality.

The foregoing comments are, I think, enough to show that Arnette did not provide verifiable answers to the issues of how the essence comes to be, what it is composed of, and what purpose it serves. We have therefore to conclude that it does not exist. It follows that the explanation of all phenomena that Arnette attributed to essencebody interaction is to be found in body-based processes themselves. This is consistent with the monistic nature of the universe as I have interpreted it, and also with the proposal made by several scientists in recent years (for example, Jantsch, 1980; Prigogine, 1980) that living systems are self-organizing systems.

Finally, I think that Arnette (1999, p. 78) has been rather too hasty in stating that near-death experiences have no survival advantage. I have pointed out how many of the elements of the NDE could be viewed as survival mechanisms (Krishnan, 1985), and so far as I know neither Arnette nor anyone else has shown that my arguments are without substance. 
